Provided by the author(s) and University of Galway in accordance with publisher policies. Please cite the published version when available.

\begin{tabular}{|c|l|}
\hline Title & $\begin{array}{l}\text { Cross-national time trends in bullying behaviour 1994-2006: } \\
\text { findings from Europe and North America }\end{array}$ \\
\hline Author(s) & Molcho, Michal \\
\hline $\begin{array}{c}\text { Publication } \\
\text { Date }\end{array}$ & 2009-06-04 \\
\hline $\begin{array}{c}\text { Publication } \\
\text { Information }\end{array}$ & $\begin{array}{l}\text { Molcho, M., Craig, W., Due, P., Pickett, W., Harel-Fisch, Y., } \\
\text { behaviour 1994-2006: findings from Europe and North } \\
\text { America. International Journal of Public Health, 54, s1-s10. }\end{array}$ \\
\hline $\begin{array}{c}\text { Publisher } \\
\text { Springer }\end{array}$ \\
\hline $\begin{array}{c}\text { Link to } \\
\text { publisher's } \\
\text { version }\end{array}$ & http://dx.doi.org/10.1007/s00038-009-5414-8 \\
\hline $\begin{array}{c}\text { Item record } \\
\text { http://hdl.handle.net/10379/2881 }\end{array}$ \\
\hline
\end{tabular}

Downloaded 2023-04-26T12:55:27Z

Some rights reserved. For more information, please see the item record link above. 


\title{
Cross-national time trends in bullying behaviour 1994-2006: findings from Europe and North America
}

\author{
Michal Molcho ${ }^{1}$, Wendy Craig ${ }^{2}$, Pernille Due ${ }^{3}$, William Pickett ${ }^{4}$, Yossi Harel-Fisch ${ }^{5}$, Mary Overpeck ${ }^{6}$ and \\ the HBSC Bullying Writing Group* \\ ${ }^{1}$ School of Health Sciences, National University of Ireland Galway, Galway, Ireland \\ ${ }^{2}$ Department of Psychology, Queen's University, Kingston, Canada \\ ${ }^{3}$ National Institute of Public Health, University of Southern Denmark, Copenhagen, Denmark \\ ${ }^{4}$ Department of Community Health and Epidemiology, Queen's University, Kingston, Canada \\ ${ }^{5}$ International Research Program on Adolescent Well-being and Health, Department of Criminology and School of Education, \\ Bar Ilan University, Ramat Gan, Israel \\ ${ }^{6}$ Michigan Public Health Institute, National Center for Child Death Review, USA
}

Submitted: 04 May 2009; accepted: 04 June 2009

\section{Abstract}

Objectives: To identify trends over 12 years in the prevalence of bullying and associated victimization among adolescents in North American and European countries.

Methods: Cross-sectional self-report surveys were obtained from nationally representative samples of 11-15 year old school children in 21 countries in 1993/94 and in 27 countries in each of 1997/98, 2001/02 and 2005/06. Measures included involvement in bullying as either a perpetrator and/or victim.

Results: Consistent decreases in the prevalence of bullying were reported between 1993/94 to 2005/06 in most countries. Geographic patterns show consistent decreases in bullying in Western European countries and in most Eastern European countries. An increase or no change in prevalence was evident in almost all English speaking countries participating in the study (England, Scotland, Wales, Ireland and Canada, but not in the USA).

Conclusion: Study findings demonstrated a significant decrease in involvement in bullying behaviour in most participating countries. This is encouraging news for policy-makers and practitioners working in the field of bullying prevention.

* Members of the HBSC Bullying Writing Group: Will Pickett (CA), Will Boyce (CA), Wendy Craig (CA), Pernille Due (DK), Bjorn Holstein (DK), Michal Molcho (IE), Yossi Harel (IL), Wilma Vollebergh (NL), Jorn Hetland (NO), Oddrun Samdal (NO), Joanna Mazur (PL), Margarida Gaspar de Matos (PT), Winfried van der Sluijs (GB-SCO), Zuzana Katreniakova (SK), Mary Overpeck (US), Tonja Nansel (US), Jing Wang (US)

\section{Introduction}

Bullying is an important and prevalent adolescent health problem in many countries, and has been the subject of considerable study over the last three decades ${ }^{1-3}$. Previous studies have demonstrated a number of adverse health outcomes associated with bullying such as psychological maladjustment ${ }^{4}$, psychosomatic health problems ${ }^{4-6}$, medicine use ${ }^{6}$, absenteeism from school ${ }^{6}$, impaired academic performance ${ }^{6}$, physical injury $^{7}$, and in rare cases, premature death ${ }^{7}$. Bullying behaviour is also associated with involvement in a range of other risk behaviours such as drinking, smoking and drug use $\mathrm{e}^{4,8-14}$. The effects of bullying are not only acute, but may also persist into later adolescence and adulthood for victims as well as perpetrators ${ }^{15-21}$. The effects of bullying are not limited to perpetrators and their victims; bystanders who witness bullying can also experience negative health outcomes ${ }^{22}$.

Despite the growing body of evidence indicating the adverse effects of bullying ${ }^{23}$, some individuals still view bullying as a minor and common problem ${ }^{24}$. Several types of bullying such as teasing, gossiping and humiliating may be dismissed as minor and therefore tolerable ${ }^{25}$. Given the severity of outcomes associated with involvement in types of bullying (either as the perpetrator or the victim) and the many prevention efforts that have been established, yet not evaluated ${ }^{1}$, it is important to investigate trends in the occurrence of bullying cross-nationally. There is much to be gained in terms of knowledge from those countries where a decrease in bullying behaviour is evident. 
To date, studies that have examined the epidemiology of bullying have been conducted at local or national levels ${ }^{27-31,8-9}$; only a few cross-national studies have been published ${ }^{5,10,32}$. To date, no existing study has presented international time trends in the occurrence of bullying. The current study therefore examines cross-national trends in the occurrence of both bullying and victimization at different levels of involvement using data from the Health Behaviour in School-Aged Children (HBSC) surveys.

Health Behaviour in School-Aged Children (HBSC) provides a unique opportunity to compare experiences with bullying across countries and over time. This WHO-collaborative survey was developed by an international network of researchers with measures, sampling, and administration procedures designed to be consistent across participating countries. The present study uses international HBSC data collected during four cycles and across 27 countries. The current analysis examines trends in the occurrence of bullying and associated victimization both temporally and geographically. It was hoped that this analysis would inform prevention efforts, by demonstrating those countries or geographic regions where the problem appears to be increasing or declining over time.

\section{Methods}

\section{Study Population and Procedures}

Initiated in 1982, the HBSC study collects data from nationally representative samples of 11-, 13- and 15-year old schoolchildren every four years in each of the participating countries (41 countries in 2006). Data are collected in the classroom using an anonymous self-administrated questionnaire, and following the common HBSC research protocol ${ }^{33}$. Classes within schools form the sampling units. Statistical criteria specify that samples submitted for international comparisons are sufficient to provide confidence intervals of $\pm 3 \%$ for representative estimates with sample design effects no more than 1.4 times greater than would be obtained from a simple random sample for each of the survey years. The current study utilized data collected from 21 countries from the 1993/1994 survey, and from 27 countries from each of the1997/1998; 2001/2002 and 2005/2006 surveys (Austria, Belgium (Flemish), Belgium (French), Canada, Czech Republic, Denmark, England, Estonia, Finland, France, Germany, Greece, Greenland, Hungary, Ireland, Israel, Latvia, Lithuania, Norway, Poland, Portugal, Russia, Scotland, Sweden, Switzerland, USA, Wales). The current analysis was based on the experiences in 27 countries, allowing for time-trend analysis over four points in time in 21 countries, and three points in time for an additional six countries. Sample sizes included in this analy- sis were 102,799 in $1993 / 94 ; 125,732$ in $1997 / 98 ; 129,240$ in 2001/02; and 133,981 in 2005/06.

Principal Investigators in each participating country obtained approval to conduct the survey from the ethics review board or equivalent regulatory body associated with the institution conducting each respective national survey.

\section{Measures}

Two mandatory questions on bullying and victimization are included in the survey, following a short paragraph that defines the concepts of bullying. The questions and the introductory paragraph were developed by Olweus ${ }^{16}$. Translation and back-translation of the prose were conducted to ensure that the meaning of each question was not lost between languages.

Bullying: In the 1993/94 and 1997/98 surveys, the question for bullying was phrased "How often have you taken part in bullying other students in school this term?" with response options 'I haven't bullied others in school this term', 'once or twice', 'sometimes', 'about once a week', 'several times a week'. In 2001/02 and 2005/06 a slightly different phrasing was used: "How often have you taken part in bullying other students at school in the past couple of months?" with response options 'I haven't bullied other students in the past couple of months', 'it has only happened once or twice', 'two or three times a month', 'about once a week', 'several times a week'.

Engagement in bullying was defined using two levels, occasional and chronic. Binary outcomes for occasional bullying were based upon responses of 'once or more' vs. 'never'. Binary outcomes for chronic bullying were 'more than twice this term' vs. 'twice or less' on the earlier version and ' 2 or more times this months' vs. 'twice or less in the last couple of months' on the later version. These cut-offs are recommended by researchers in the field ${ }^{17}$.

Victimization from bullying: Questions about being bullied (victimization) and response categories were analogous to those for bullying. The question on bullying victimization was changed between 1997/98 and 2005/06 from "How often have you been bullied in school this term?" with response options 'I haven't been bullied in school this term', 'once or twice', 'sometimes', 'about once a week', 'several times a week', to 'How often have you been bullied at school in the past couple of months?" with response options 'I haven't been bullied in the past couple of months', 'it has only happened once or twice', 'two or three times a month', 'about once a week', 'several times a week'. Bullying victimization was examined at two levels, occasional and chronic (as above).

Data analyses were initially conducted with SPSS 15 (SPSS Inc, Chicago, IL). A conservative design effect of 1.4 was 


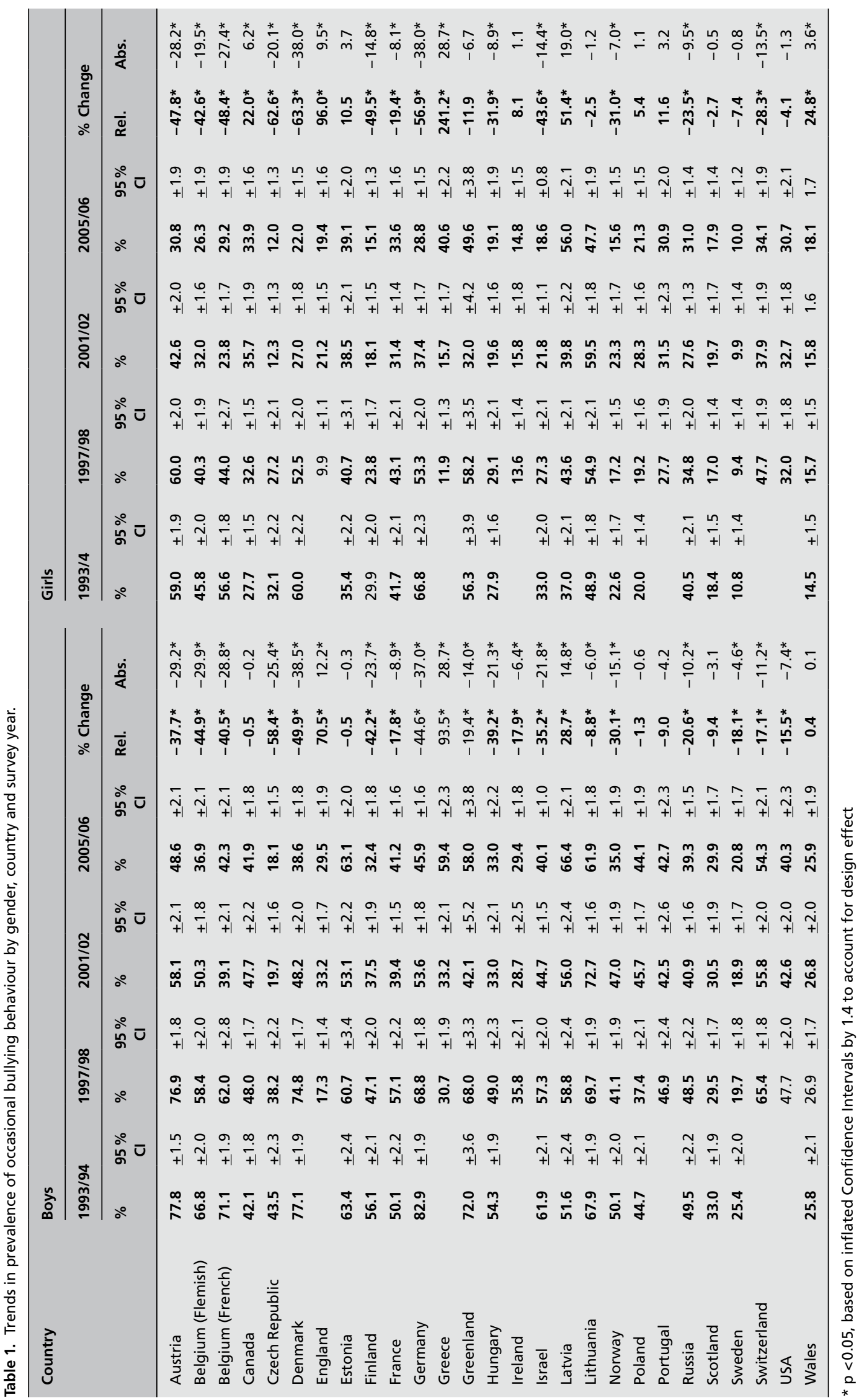




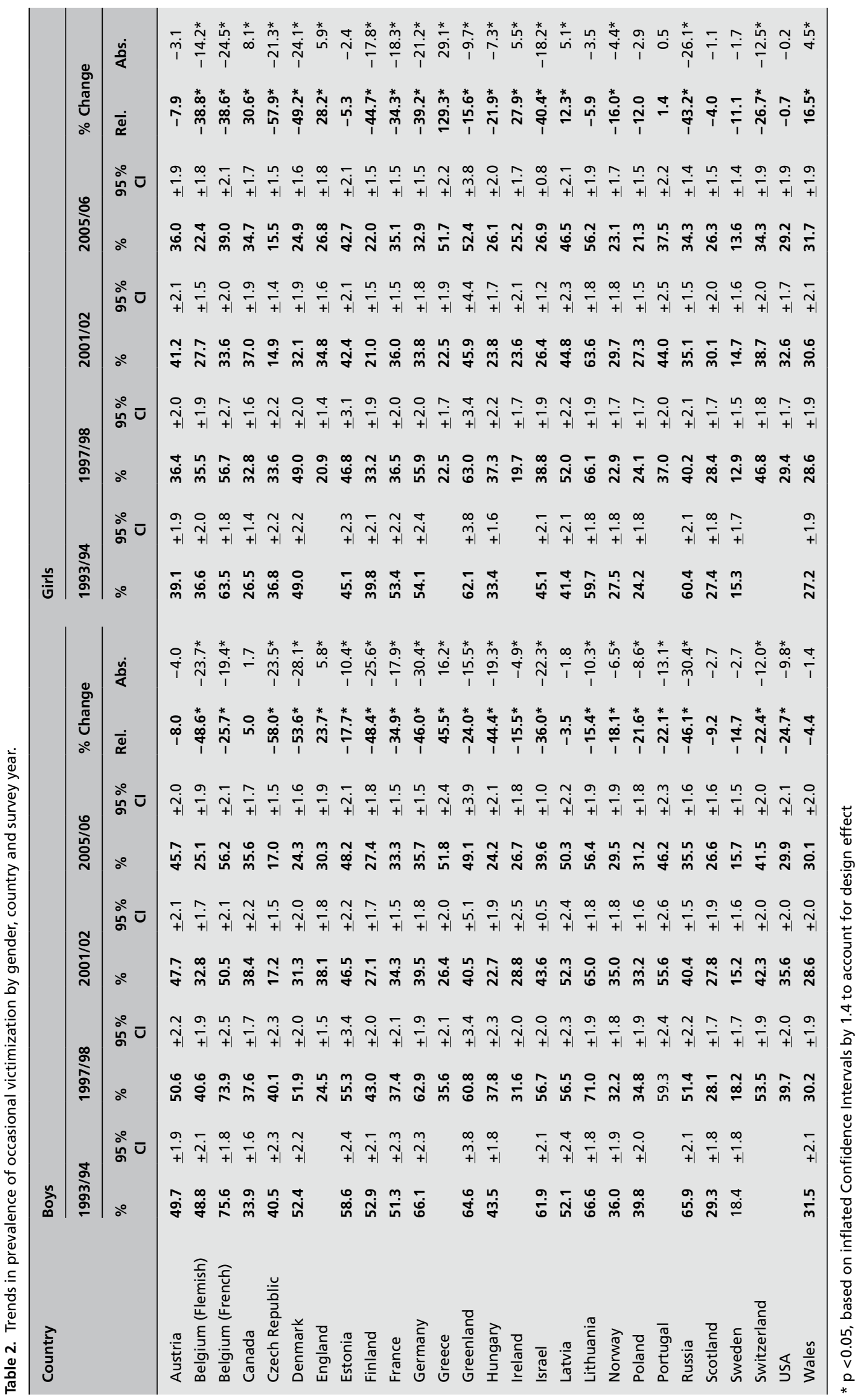




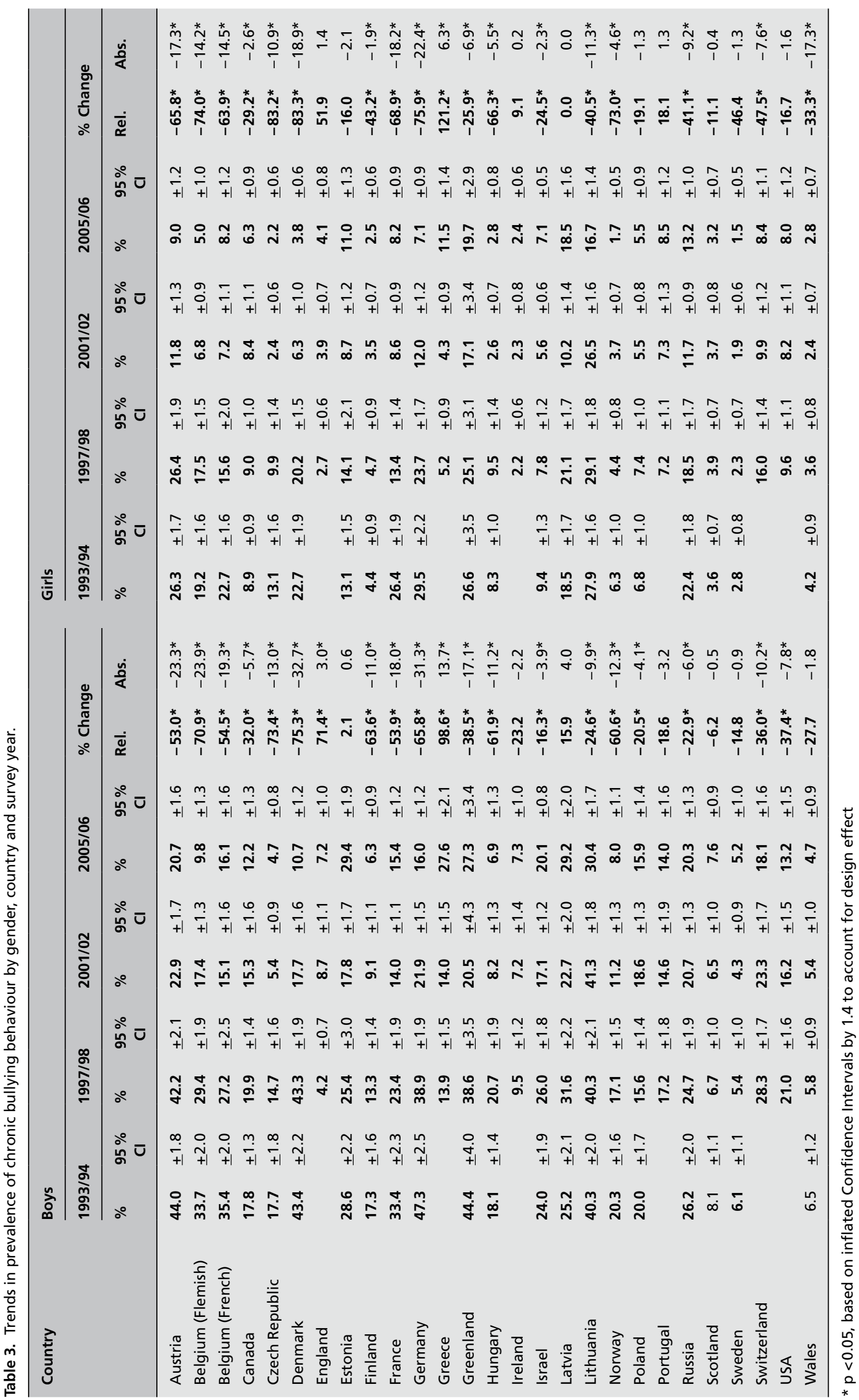


used in the inflation of standard error estimates and associated $95 \%$ confidence intervals to account for the cluster-based sampling ${ }^{33}$. The prevalence of young people that reported bullying others or being a victim of bullying at the two severity levels (occasional, chronic) were calculated for each participating country by gender and survey year. Statistical differences in reported rates between survey years were inferred from non-overlapping confidence intervals. For each of the measures, the prevalence and the time trends are presented in alphabetic order by country and gender, together with absolute changes (percentages) and relative changes (percentage points). A summary of the overall trend in rates over time is then presented.

\section{Results}

Table 1 presents the prevalence of occasional bullying by country and gender. The largest decrease was reported in the Czech Republic, with a $58.4 \%$ relative decrease among boys (from $43.5 \%$ in $1993 / 94$ to $18.1 \%$ in $2005 / 06$ ) and $62.6 \%$ among girls (from $32.1 \%$ to $12.0 \%$ ), followed by Denmark with $49.9 \%$ decrease among boys (from $77.1 \%$ to $38.6 \%$ ) and $63.3 \%$ among girls (from $60.0 \%$ to $22.0 \%$ ). Pronounced increases in the prevalence of bullying are evident in Greece and England between 1997/98 and 2005/06

Similar to occasional bullying, decreases in occasional victimization were evident in most countries (Table 2). These were mainly attributable to changes observed between 1997/98 and 2001/02. The largest relative decrease is found in the Czech Republic and the largest increases were found in Greece and England. Interestingly, in most countries when a change was evident (whether decrease or increase) it was larger among girls.

Overall, the percentage of children involved chronically in the bullying of others decreased over the years from $19.3 \%$ in $1993 / 94$, through $16.1 \%$ in $1997 / 98$ and $11.1 \%$ in $2001 / 02$, to $10.6 \%$ in $2005 / 06$. Decreases in these percentages were reported in 19 countries over the entire study period. As expected with the overall lower prevalence of chronic bullying, in most countries, decreases in the absolute prevalence of bullying were smaller than for the measures of occasional bullying. However, the relative percentage change in chronic bullying is larger than that of occasional bullying (Table 3). Similar country patterns are evident, with the largest decreases evident in the Czech Republic and Denmark, and the largest increases observed in Greece and England. Decreases in chronic victimization were mainly evident between 1993/94 and 1997/98. Decreases observed subsequent to those cycles were smaller in absolute terms, but statistically significant in
19 of the 27 countries. In relative terms, decreases in the prevalence of chronic victimization in both genders were more pronounced than that reported for occasional victimization (Table 4)

Overall, decreases in reported rates of bullying and victimization were observed in the majority of the 27 participating countries. Significant decreases in occasional bullying were reported in 16 countries over the study period. Significant decreases in the prevalence of occasional victimization and in the prevalence of chronic bullying were reported in 19 countries. Significant decreases in chronic victimization were reported in 21 countries. No significant changes were reported in 5-8 countries on all measures. Increases in rates of bullying were reported in 1 to 3 countries on all measures, although most of these changes were small (Table 5).

With respect to geographic patterns, decreases in bullying behaviour were reported over time in countries from the following areas: Scandinavia, Eastern Europe, most of Western Europe, and the Baltic countries. In English speaking countries in Europe and in North America, slight increases or no changes were reported over time for most measures. No clear patterns were evident in South/Mediterranean Europe, represented by three countries only. A decrease was reported in Israel for all measures, while increases were reported in Greece and no consistent changes in Portugal.

\section{Discussion}

Bullying and associated victimization are common in almost all participating countries. A third of the children in the overall sample report occasional bullying or victimization, and around 1 in 10 children report chronic involvement in bullying, either as a perpetrator or as a victim. The findings also reveal substantial cross-national differences in reports of bullying, with lows of $14.6 \%$ and $15.4 \%$ reporting victimization and bullying in Sweden, and highs of $56.3 \%$ and $54.9 \%$ reporting victimization and bullying in Lithuania.

Although cross-national variations in reports of bullying are evident, it is also clear that in most countries involvement in bullying behaviour is decreasing over time. As expected, when presented in absolute terms, these decreases appear to be more pronounced in the more prevalent 'occasional' category. However, when presented in relative terms, decreases in chronic bullying are as large, if not larger, than that of the occasional categories.

Significant variations were observed between countries with respect to the observed trends in rates of bullying and victimization. Speculatively, these variations may be due to national or more local prevention efforts. There are many potential 


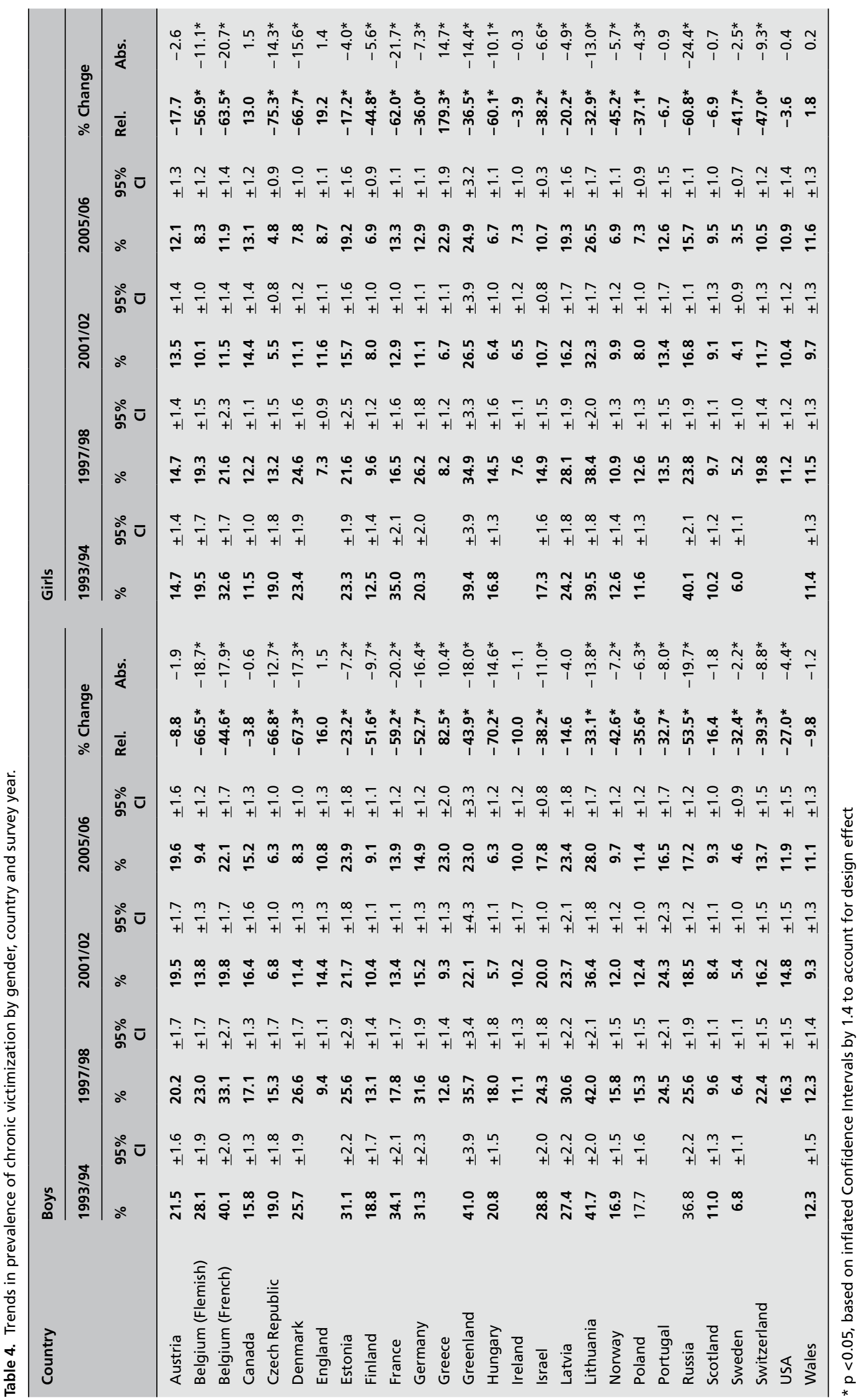




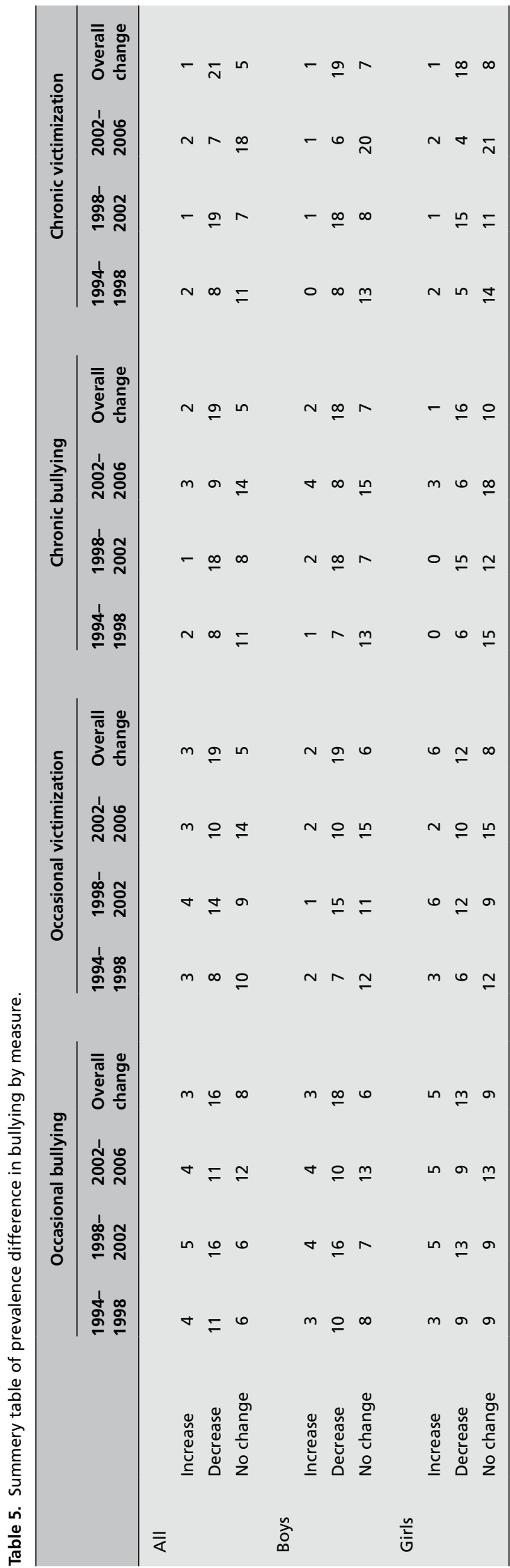

lessons for current interventional efforts to be learned from countries such as Denmark, the Czech Republic and Belgium that reported significant decreases in bullying and victimization. Similarly, there is much to be learned from countries such as Sweden where the prevalence of bulling was low at the baseline and remained so over the full study period.

Some important geographic patterns were identified in this analysis. All of the Western European countries reported consistent decreases for each of the four measures of bullying. Such consistent findings were not evident in any other region. In the Eastern European countries, a pattern indicating a decrease was also reported for most measures. Southern/Mediterranean European countries showed no consistent pattern, although the lack of clear geographical pattern in this region could be attributed to the low number of countries represented.

The most intriguing geographic finding related to participating Northern European countries. In all four of the Scandinavian countries, the prevalence of bullying behaviour decreased across each of the four measures. Interestingly, in these countries there are ongoing focussed national efforts to address bullying ${ }^{34}$. Similarly, a decrease was evident in the Baltic region countries with the exception of Latvia, bringing the prevalence in those countries closer to that of Northern Europe. No such pattern, however, is evident in the English speaking countries (except for the US which instituted a national anti-bullying campaign due to HBSC survey results). With an increase on most bullying measures in England and Canada and no change or only a slight decrease in Ireland, Scotland and Wales, these countries stand out from the rest of the countries in Europe in relation to patterns of bullying behaviours. However, the prevalence of bullying in most countries in Great Britain and Ireland was relatively low at baseline, leaving little room for decline.

Findings yielded from the HBSC study over a period of 12 years ( 8 years for 6 of the countries) suggest that both bullying and victimization, mild and severe, are decreasing in as many as 20 countries of the 27 studied. These findings send a positive message regarding current prevention and health promotion efforts. The reported decreases could be a consequence of ongoing efforts to address school bullying, the result of the increased awareness, or both. Increased awareness about the public health and social significance of bullying may have changed attitudes and tolerance towards bullying among populations that previously disregarded the significance of the problem $^{24,25}$. Finally, decreases could reflect actual changes in bullying behaviours.

The lack of observed decreases in bullying in most English speaking countries that is reflected in English speaking media, however, may play a role in the global perception of in- 
crease in bullying prevalence. As is clearly evident in Stassen Berger $^{1}$ review, research in the area of bullying also has increased dramatically over the last twenty years, demonstrating its adverse effects. This research may have provided support for both youth and adults working with youth to address this significant social problem. The combination of empirical evidence highlighting the significance of the problem, and the increased prevention and intervention efforts to address the problem of bullying, may explain the significant decline the prevalence of the problem in many countries, in a manner that was thus far restricted due to the limited scientific evaluation of existing interventional efforts ${ }^{1}$.

\section{Strengths and limitations}

The HBSC study offers a unique opportunity for cross-national and temporal investigations of adolescent health problems. Standardization of study methods allows, for the first time, an extensive study of temporal patterns of bullying behaviour reported across countries. At the same time, the cross-cultural nature of the research and the translation of the questionnaires into a large number of languages, even if followed by thorough back translation, may have led to some information bias. Definitions and perceptions of bullying may vary by cultural setting and contribute to observed cross-national variations ${ }^{5,35}$. However, because of similarities in the measures used, these variations are not expected to change over time. As the main purpose of this study was to examine changes within countries, such bias is of lesser importance in the present analysis. Similarly, there is a potential for a self-report bias. The HBSC instruments are subjected to ongoing validation efforts, yet the possibility of biased reporting motivated by a desire to provide socially desirable responses must be recognized.

The slight change in the wording of the bullying items, starting in the 2001/02 study, undoubtedly had some effects on the study results. The recall period for the two questions changed from 'last term' to the 'last couple of months'. For many of the countries, the timing of data collection created an overlap between 'last term' and the 'last couple of months'. For these countries, this change in wording would make little difference. However, in other countries this change would make comparisons across years more challenging, especially in relation to the chronic bullying outcome. Changes in the wording of the question could have lead to a spurious decrease in the prevalence of bullying, however, in most countries the decrease in bullying is evident prior to the change in the wording of the questions and continues after it.

Finally, although HBSC enables both cross-national and temporal comparisons, the study does not provide background information on the cultural context of each country or on different national strategies, policies or intervention / prevention programmes that address the problem of bullying. In the absence of this information, it is difficult to provide further explanation surrounding the contexts that lead to any observed changes. As much as this limits the knowledge that can be gained from our findings, it does not diminish the importance of the findings.

In conclusion, findings presented in this paper demonstrate a clear and significant decrease in involvement in bullying behaviour in most European and North American countries. Whereas bullying was identified as an international problem, the findings suggest that reported decreases in this behaviour are cross-national as well. These findings should send an encouraging massage to policy makers and practitioners in the field of bullying prevention. Although bullying is not eradicated as of yet, chronic bullying is becoming a much less common phenomena when compared with the past. The study also identified selected countries where an observed decrease in bullying behaviour was more substantial. Such information calls for further investigation into interventions used in those countries, with the hope of transfer of this knowledge to other countries that have not experienced substantial declines in bullying.

\section{Acknowledgements}

HBSC is an international study carried out in collaboration with WHO/EURO. The International Coordinator of the 1997/98, 2001/02 and 2005/2006 studies was Candace Currie (Bente Wold was the International Coordinator in 1993/94), University of Edinburgh, Scotland and the data bank manager of the 2001/02 and 2005/2006 studies was Oddrun Samdal, University of Bergen, Norway (Bente Wold was the International Coordinator in 1993/94 and 1997/98). A complete list of the participating researchers can be found on the HBSC website (www.HBSC.org).

We thank the HBSC International Coordinating Centre, University of Edinburgh and all of the investigators of the participating countries. 


\section{References}

1. Stassen Berger K. Update on bullying at school: science forgotten? Dev Rev 2007; 27:90-126.

2. Stanton B, Baldwin RM, Rachuba L. A quarter century of violence in the United States. An epidemiologic assessment. Psychiatr Clin North Am. 1997; 20:269-82.

3. Eisenbraun KD. Violence in schools: prevalence, prediction and prevention. Aggress Violent Behav 2007;12:459-69.

4. Nansel TR, Overpeck M, Pilla RS, Ruan WJ, Simons-Morton BG. Bullying behaviors among US youth: prevalence and association with psychosocial adjustment. J Am Med Assoc 2001;285:2094-100

5. Due P., Holstein BE., Lynch J.W, et al. Bullying and symptoms among school-aged children: international comparative cross sectional study in 28 countries. Eur J Pub Health 2005;15128-32.

6. Due P, Hansen EH, Merlo J, Andersen A, Holstein BE. Is victimization from bullying associated with medicine use among adolescents? A nationally representative cross sectional survey in Denmark. Pediatrics 2007;120:110-7.

7. Kaltiala-Heino R, Rimpela M, Rantanen $P$, Rimpela A. Bullying at school - an indicator of adolescents at risk for mental disorders. J Adolesc 2000;23:661-74.

8. Molcho M, Harel Y, Dina LO. Substance use and youth violence. A study among 6th to 10 th grade Israeli school children. Int J Adolesc Med Health 2004;16:239-51.

9. Mazur J, Malkowska A.Bullies and victims among Polish school-aged children. Med Wieku Rozwoj 2003;7:121-34.

10. Nansel TR, Craig W, Overpeck MD, Saluja G, Ruam J and the Health Behavior in School aged Children Bullying analyse group. Cross national consistency in the relationship between bullying behaviors and psychosocial adjustment. Arch Pediatr Adolesc Med 2004;156:730-6.

11. Forero R, McLellan L, Rissel C, Bauman A. Bullying behaviour and psychosocial health among school students in New South Wales, Australia: cross sectional survey. BMJ 1999;344-9.

12. Wolke D, Woods S, Stanford K, Schulz H. Bullying and victimization of primary school children in England and Germany: prevalence and school factors. Br J Psychol 2001;92:673-96.

13. Karatzias A, Power KG, Swanson V. Bullying and victimisation in Scottish secondary schools: same or separate entities? Aggress Behav 2002;28:45-61.
14. Beale AV. 'BullyBusters': using drama to empower students to take a stand against bullying behavior. Professional School Counselling 2001;4: 300-5.

15. Bond L, Carlin JB, Thomas L, Rubin K, Patton G. Does bullying cause emotional problems? A prospective study of young teenagers. BMJ 2001;323: 480-4.

16. Olweus D. Bullying among schoolchildren: intervention and prevention. In: Peters RD,

McMahon RJ, Quinsey VL, eds. Aggression and violence throughout the life span. Newbury Park: Sage Publications;1992:100-25.

17. Olweus D. Bullying at school: long-term outcomes for the victims and an effective schoolbased intervention program. In: Huesmann LR, ed. Aggressive behavior: current perspectives. New York: Plenum Press:1994:97-130.

18. Osofsky HJ, Osofsky JD. Violent and aggressive behaviors in youth: a mental health and prevention perspective. Psychiatry 2001; 64:285-95.

19. Kaliala-Heino R, Rimpela M, Marttunen $M$, Rimpela A, Rantanen P. Bullying, depression, and suicidal ideation in Finnish adolescents: school survey. BMJ 1999;319:348-51.

20. Simon TR, Dent CW, Sussman S. Vulnerability to victimization, concurrent problems behaviors, and peer influence as predictors of in-school weapon carrying among high school students. Violence Victims 1997;1999:100-27.

21. Clapper RL, Buka SL, Goldfield, Lipsitt LP, Tsuang MT. Adolescent problem behaviors as predictors of adult alcohol diagnoses. Int J Addict 1995;30:507-23.

22. Black SA, Jackson E. Using bullying incident density to evaluate the Olweus Bullying Prevention Programme. Sch Psychol Int 2007; 28:623-38.

23. Hawker DSJ, Boulton MJ. Twenty years' research on peer victimization and psychological maladjustment: meta-analytic review of crosssectional studies. J. Child Psychol. Psychiat 2000:41:441-55.

24. Tolan PH. International trend in bullying and children's health. Arch Pediatr Adolesc Med 2004;158:831-2.

25. Bulach C, Fulbright JP, Williams R. Bullying behaviour: what is the potential for violence at your school?. J Instr Psychol 2003;30:156-64.

26. Rigby K. Consequences of bullying in schools. Can. J. Psychiatry 2003;48:583-90.
27. Due P, Holstein BE, Schultz Jørgensen P. Bullying as health threat among schoolchildren. Ugeskr Laeger 1999:161:2201-6.

28. Nansel TR, Overpeck MD, Haynie DL, Ruan J, Scheidt PC. Relationships between bullying and violence among US youth. Arch Pediatr Adolesc Med 2003;157:348-53.

29. Volk A, Craig WM, Boyce W, King M. Perceptions of parents, mental health, and school amongst Canadian adolescents from the Provinces and the Northern Territories. Can J School Psychol 2006;21:33-46.

30. Zaborskis A, Cirtautiene L, Žemaitiene N. Bullying in Lithuanian schools in 1994-2002. Medicina (Kaunas) 2005;41:614-20.

31. Schnohr C, Niclasen BV. Bullying among Greenlandic schoolchildren: development since 1994 and relations to health and health behaviour. Int J Circumpolar Health 2006;65:305-12.

32. Due $P$, Holstein BE. Bullying victimization among 13 to 15 year old school children: results from two comparative studies in 66 countries and regions. Int J Adolesc Health Med 2008;20: $208-21$.

33. Currie $\mathrm{C}$, Nic Gabhainn S, Godeau E, et al. Inequalities in young people's health: HBSC international report from the 2005/2006 Survey. Copenhagen, WHO Regional Office for Europe, 2008

34. Nordhagen R, Nielsen A, Stigum H, Kohler L. Parental reported bullying among Nordic children: a population-based study. Child Care Health Dev 2005;31:693-701.

35. Harel Y. A cross-national study on youth violence in Europe. Int J Adolesc Med Health 1999:11:121-34.

Address for correspondence

Michal Molcho, PhD

School of Health Sciences

National University of Ireland Galway

Galway

Ireland

Tel.: 35391493668

Fax: 35391494577

E-mail: Michal.molcho@nuigalway.ie 